\title{
Patrones de progreso técnico en la economía brasileña, 1952-2008
}

\author{
Adalmir Marquetti y Melody de Campos Soares Porsse
}

RESUMEN

En este artículo se analiza el patrón de progreso técnico en la economía brasileña entre 1952 y 2008. El patrón de progreso sesgado en el sentido de Marx, ahorrador de trabajo y consumidor de capital, predominó en el período estudiado. Sin embargo, se distinguen tres fases en el dinamismo del progreso técnico. La primera, de 1952 a 1973 se caracteriza por un gran dinamismo. En la segunda, de 1973 a 1991, dicho dinamismo disminuyó. Finalmente, entre 1991 y 2008, el dinamismo de los cambios técnicos repuntó levemente. La parte salarial se mantuvo relativamente estable durante todo el período. La tasa de ganancia decreció entre 1952 y 1991, y se acrecentó ligeramente de 1991 a 2008. La tasa neta de acumulación de capital se contrajo después de 1975 debido a la caída de las tasas de ganancia e inversión. Entre 2004 y 2008, aumentó la tasa neta de acumulación de capital.

PALABRAS CLAVE

CLASIFICACIÓN JEL

AUTORES
Crecimiento económico, productividad, desarrollo industrial, capital, formación de capital, ingresos, salarios, Brasil

$\mathrm{B} 14, \mathrm{O} 33, \mathrm{O} 40$

Adalmir Marquetti es profesor titular en el Departamento de Economía de la Pontificia Universidad Católica de Rio Grande do Sul, Brasil. aam@pucrs.br

Melody de Campos Soares Porsse es profesora suplente del Departamento de Administración General y Aplicada de la Universidad Federal de Paraná, Brasil. msporsse@gmail.com 


\section{I}

\section{Introducción}

En los últimos sesenta años, el Brasil ha pasado por dos fases completamente distintas en lo relativo al crecimiento económico. Entre 1952 y 1980, el país tuvo una de las economías más dinámicas del mundo, con una tasa de crecimiento del producto interno bruto (PIB) superior al 7\% anual. Entre el final de la Segunda Guerra Mundial y 1980, el crecimiento fue impulsado por el sector industrial, en un marco de industrialización mediante sustitución de importaciones liderado por el Estado. La erosión de ese proceso de industrialización se inició en 1973, cuando la crisis de la "edad de oro" se hizo sentir en la economía brasileña debido al creciente empeoramiento de las condiciones de rentabilidad y de acumulación de capital.

En la segunda fase, de 1980 a 2003, el crecimiento se redujo hasta el $2 \%$, con una caída aproximada de cinco puntos porcentuales. De este modo, el crecimiento económico brasileño fue muy exiguo en la década de 1980, la llamada década perdida, y durante los años noventa. Corregido por el ciclo económico, el crecimiento del PIв brasileño fue del 2,2\% anual entre 1980 y 1990, y del 2,3\% entre 1990 y 2003. Esto contrasta con las significativas modificaciones políticas —el proceso de redemocratización y la promulgación de la Constitución Política de la República Federativa del Brasil de 1988y económicas que se produjeron durante ese período. Desde el punto de vista económico, los cambios más relevantes fueron la apertura comercial y financiera, el control de la inflación con el Plan Real en 1994, el proceso de privatización y reducción del papel del Estado en la actividad económica y la adopción del programa de metas de inflación en 1999. Los cambios económicos a comienzos de los años noventa significaron el fin del proceso de industrialización mediante sustitución de importaciones en el país.

La economía internacional también experimentó grandes cambios institucionales y tecnológicos a partir de 1980. En el ámbito institucional, se produjeron reformas con el objetivo de volver a convertir el mercado en el mecanismo fundamental de asignación de recursos y, en consecuencia, de reducir el papel del Estado en ese proceso. En cuanto al patrón tecnológico, las nuevas tecnologías de la información y las comunicaciones (TIC) permitieron aumentar la productividad del trabajo y del capital, especialmente en combinación con cambios organizativos en las empresas. El proceso de globalización, por su parte, supuso un creciente flujo de capitales y mercancías entre los países.

El progreso técnico es el principal factor de crecimiento de un país. Los autores clásicos, Smith y Ricardo, así como Marx, fueron los pioneros en el estudio del patrón de incorporación del progreso técnico y la evolución de la productividad a largo plazo. Smith investigó los efectos de la división del trabajo en la productividad. Ricardo analizó, en el capítulo sobre la maquinaria, los efectos de la sustitución del trabajo por el capital en la distribución de los ingresos y en el empleo. Marx asoció el análisis del desarrollo capitalista con el patrón de progreso técnico. Para este autor, la forma de producir se ve constantemente alterada en el capitalismo por la introducción de innovaciones técnicas para obtener una superganancia. Marx consideró que la disputa entre capitalistas y trabajadores sobre el valor agregado constituye un incentivo sistemático para que el progreso técnico adquiera una forma sesgada: ahorrador de trabajo y consumidor de capital.

Según el análisis de Marx, la mecanización sería la forma típica de progreso técnico de las economías capitalistas y los aumentos de la productividad del trabajo se lograrían mediante la reducción de la productividad del capital, con la consiguiente caída de la tasa de ganancia si se mantiene constante la distribución del ingreso. Foley y Michl (1999) denominan un progreso técnico sesgado, en el sentido de Marx, a los cambios técnicos que ahorran trabajo y consumen capital. Este patrón aunque es similar al progreso técnico neutro en el sentido de Harrod (dado que ambos son ahorradores de trabajo y consumidores de capital), son distintos en sus dinámicas, tal como se explica más adelante. El progreso técnico sesgado en el sentido de Marx también difiere del progreso técnico neutro en el sentido de Solow, que es consumidor de trabajo y ahorrador de capital, así como del progreso técnico neutro en el sentido de Hicks, que ahorra tanto trabajo como capital.

En el presente estudio se investigan los patrones de progreso técnico en la economía brasileña entre 1952 y 2008 y la forma en que esos patrones se relacionan con el crecimiento del país. Los patrones de progreso técnico se analizan utilizando la relación distribución-crecimiento, una recta que marca la productividad del trabajo en la 
intersección con el eje de ordenadas y la productividad del capital en la intersección con el eje de abscisas. La relación distribución-crecimiento se basa en la curva de salario y ganancia de Sraffa (1960) y permite visualizar patrones de progreso técnico a lo largo del tiempo.

Este estudio se organiza de la siguiente manera: luego de la Introducción, en la sección II se presenta un sistema de estudio del progreso técnico. En la sección III se aborda el progreso técnico en la economía del Brasil de 1952 a 2008, en tanto que la sección IV se refiere a la rentabilidad, la distribución y el progreso técnico. La sección $\mathrm{V}$ se enfoca en la acumulación de capital y progreso técnico. Por último, en la sección VI se entregan las consideraciones finales.

\section{II}

\section{Un sistema de estudio del progreso técnico y de su representación}

Para estudiar el progreso técnico, se considera que la economía solo produce una mercancía utilizando capital y trabajo. La técnica de producción se representa mediante la relación distribución-crecimiento. Entre los estudios que emplean dicha relación para analizar el comportamiento simultáneo de las productividades del trabajo y del capital destacan, por ejemplo, Foley y Michl (1999); Foley y Marquetti (1997 y 1999); Marquetti (2002), Ferretti (2008) y Felipe, Laviña y Fan (2008).

Para un año dado, $X$ es el PIB; $K$ es la masa neta de capital fijo no residencial medida en la misma unidad del PIB; $C$ representa el consumo agregado que incluye todos los ingresos que no sean inversión bruta, $I$ es la inversión bruta, $D$ simboliza la depreciación y $N$ el número de trabajadores empleados; $W$ es la compensación total de los trabajadores; $Z=X-W$ es la ganancia bruta y $R=Z-D$ la ganancia neta, en tanto que $Y=X-D$ representa el producto neto.

Al comparar la evolución de los países a lo largo del tiempo, resulta preferible expresar las medidas absolutas en términos de relaciones. De esta forma, $x=X / N$ es el PIB por trabajador o la productividad del trabajo; $k=K / N$ representa el capital por trabajador o la intensidad de capital; $w=W / N$ es el salario medio real; $c=C / N$ es el consumo social por trabajador, mientras que $i=I / N$ simboliza la inversión por trabajador. Otras variables se expresan en términos de masa de capital: $p=X / K=x / k$ es el producto por unidad de capital o la productividad del capital; $v=Z / K=z / k$ es la tasa bruta de ganancia y $r=v-d$ es la tasa neta de ganancia; $g_{K}+d=I / K$ es la tasa de acumulación, es decir, la relación entre inversión bruta y la masa de capital, y $d=D / K$ es la tasa de depreciación. La tasa de crecimiento de cualquier variable, por ejemplo de la productividad del trabajo, se denomina $g_{x}=\Delta x / x$, mientras que $g_{p}$ representa la tasa de crecimiento de la productividad del capital. La participación de las ganancias en la renta nacional es $\pi=z / x$ y la de los salarios es $1-\pi=w / x$.

La relación distribución-crecimiento (véase el gráfico 1) es una forma de representar los componentes de las cuentas nacionales para un período dado. En lo referente al gasto, el punto $\left(g_{K}+d, c\right)$ muestra la distribución de la productividad del trabajo entre inversión y consumo, $x=c+i=c+g_{k} k+d k=c+\left(g_{K}+d\right) k$. Cuando se invierte la totalidad del producto, la tasa de acumulación alcanza el valor máximo posible, que es igual a la productividad del capital. Por otra parte, el consumo social por trabajador es igual a la productividad del trabajo cuando se consume todo el producto. En cuanto al ingreso, el punto $(r+d, w)$ muestra la distribución de la productividad del trabajo entre ganancias y salarios, $x=w+z=w+r k+d k=w+(r+d) k$. La tasa de ganancia máxima, cuando todo el producto toma la forma de ganancia, es igual a la productividad del capital. A su vez, el salario máximo, cuando todo el producto toma la forma de salarios, es igual a la productividad del trabajo.

La tecnología está formada por el conjunto de técnicas de producción conocidas. Cada técnica de producción se describe mediante la productividad del trabajo, la productividad del capital y la tasa de depreciación. El patrón de progreso técnico se analiza por medio de la combinación de los cambios de las productividades del trabajo y del capital. El progreso técnico es ahorrador de trabajo si aumenta la productividad laboral y es consumidor de trabajo en el caso contrario. A su vez, el progreso técnico es ahorrador de capital si incrementa la productividad del capital y consumidor de este si disminuye la productividad del capital. Por lo 
GRÁFICO 1
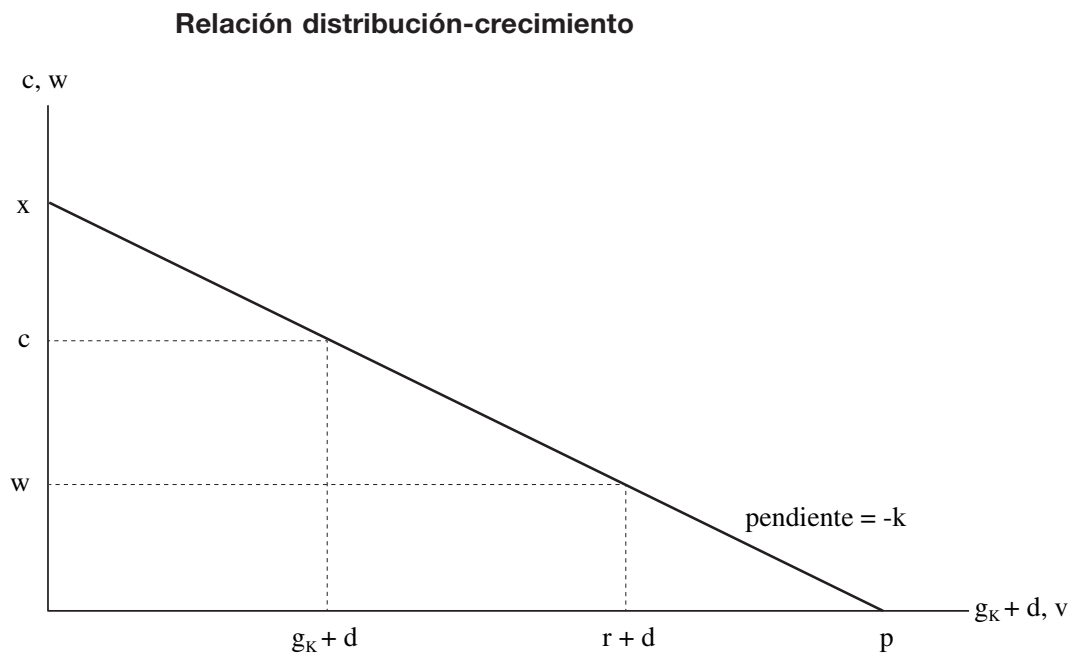

Fuente: D. Foley y T. Michl, Growth and Distribution, Cambridge, Harvard University Press, 1999.

Nota: $\mathrm{x}$ es la productividad del trabajo; $\mathrm{k}$ representa la intensidad de capital; w es el salario medio real; c es el consumo social por trabajador; $\mathrm{p}$ es la productividad del capital; $v$ es la tasa bruta de ganancia; $r$ es la tasa neta de ganancia; gk $+\mathrm{d}$ es la tasa de acumulación, y d es la tasa de depreciación.

tanto, es posible analizar los distintos tipos de progreso técnico a lo largo de un período determinado observando los cambios de la relación distribución-crecimiento.

En la literatura relacionada hay tres tipos de progreso técnico. El progreso técnico neutro en el sentido de Harrod o puramente ahorrador de trabajo corresponde a un aumento de la productividad laboral, manteniendo constante la productividad del capital. Este patrón se representa mediante una rotación de la relación distribución-crecimiento de la técnica $\mathrm{B}$ a la técnica $\mathrm{C}$ en el gráfico 2. El progreso técnico neutro en el sentido de Solow o puramente ahorrador de capital corresponde a un aumento de la productividad del capital, manteniendo constante la productividad del trabajo, y se representa mediante una rotación de la relación distribución-crecimiento de la técnica $\mathrm{A}$ a la técnica B. El progreso técnico neutro en el sentido de Hicks o ahorrador tanto de capital como de trabajo corresponde al caso en que la productividad laboral crece a la misma velocidad que la productividad del capital. Este patrón está representado por un desplazamiento paralelo de la relación distribución-crecimiento de la técnica A a la técnica $\mathrm{C}$, manteniendo constante la relación entre capital y trabajo.

A su vez, el progreso técnico sesgado en el sentido de Marx corresponde al caso en que la productividad del trabajo crece y la del capital disminuye, de acuerdo con el gráfico 3. Según Marx, la disputa entre el capitalista y el trabajador con respecto al valor agregado constituye un poderoso incentivo para que los cambios técnicos sigan un patrón ahorrador de trabajo y consumidor de capital, en que la creciente utilización de máquinas y equipos sustituye al trabajo de los seres humanos. Según este punto de vista, la mecanización sería el patrón de cambio técnico en la economía capitalista, con aumento de la productividad del trabajo y reducción de la productividad del capital. Foley y Michl (1999) denominan a este tipo de cambio técnico un progreso técnico sesgado en el sentido de Marx. Manteniendo constante la distribución funcional de los ingresos, si el progreso técnico es sesgado en el sentido de Marx, se produce una reducción de la tasa de ganancia. Debido a la contracción de dicha tasa, disminuyen también las tasas de acumulación de capital y de crecimiento económico.

Por lo tanto, en el patrón de progreso técnico sesgado en el sentido de Marx se prevén las siguientes tendencias a largo plazo:

i) aumento de la productividad del trabajo, reducción de la productividad del capital y crecimiento de la intensidad del capital;

ii) declive de la tasa de ganancia y relativa estabilidad de la participación correspondiente a los salarios;

iii) incremento del salario real;

iv) disminución de la tasa de acumulación, y

v) aumento del producto y del empleo. 
GRÁFICO 2

\section{Conceptos de progreso técnico neutro y cambios de la relación} distribución-crecimiento

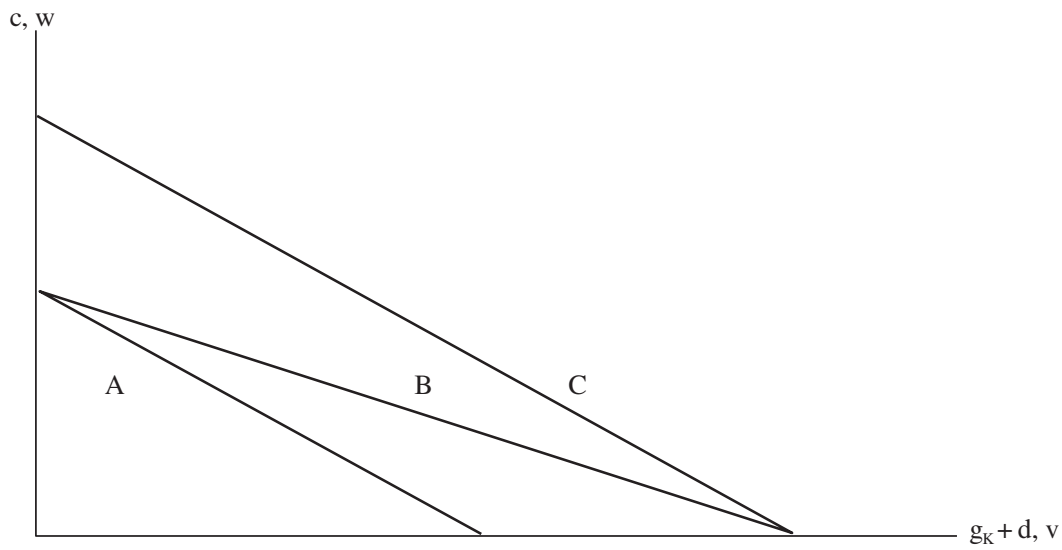

Fuente: A. Marquetti, "Progresso técnico, distribuição e crescimento na economia brasileira: 1955-1998", Estudos econômicos, vol. 32, $\mathrm{N}^{\circ}$ 1, São Paulo, Universidad de São Paulo, 2002.

Nota: w es el salario medio real; c es el consumo social por trabajador, y v es la tasa bruta de ganancia. El progreso técnico neutro en el sentido de Harrod se representa mediante una rotación de la relación distribución-crecimiento de la técnica A a la técnica B. El progreso técnico neutro en el sentido de Solow se indica mediante una rotación de la técnica $\mathrm{B}$ a la técnica $\mathrm{C}$. El progreso técnico neutro en el sentido de Hicks está representado por un desplazamiento de la técnica A a la técnica C, manteniendo constante la relación entre capital y trabajo.

GRÁFICO 3

\section{El progreso técnico sesgado en el sentido de Marx y la relación distribución-crecimiento}

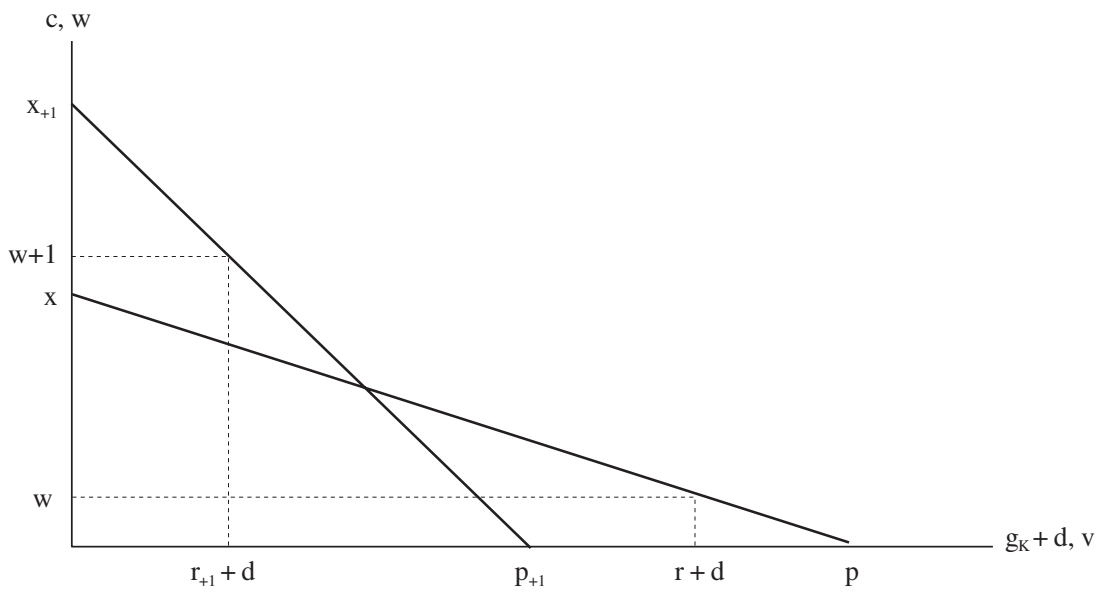

Fuente: A. Marquetti, "Progresso técnico, distribuição e crescimento na economia brasileira: 1955-1998", Estudos econômicos, vol. 32, $\mathrm{N}^{\circ}$ 1, São Paulo, Universidad de São Paulo, 2002.

Nota: x es la productividad del trabajo; w es el salario medio real; c es el consumo social por trabajador; $\mathrm{p}$ es la productividad del capital; $\mathrm{v}$ es la tasa bruta de ganancia; $r$ es la tasa neta de ganancia, y d es la tasa de depreciación. 
Resulta evidente que las tendencias históricas, como se señala en Duménil y Lévy (2003), están relacionadas entre sí e involucran diferentes aspectos de la teoría económica. En el gráfico 4 se ilustran de forma muy simplificada las principales relaciones entre las variables. La técnica utilizada y la distribución de los ingresos determinan la tasa de ganancia. La distribución de los ingresos afecta también a las decisiones de ahorro e inversión de los capitalistas. La tasa de ganancia, suponiendo que una parte de las ganancias sea ahorrada e invertida, determina la acumulación del capital. La tasa de ganancia influye también en la elección de las técnicas utilizadas. Se adopta una nueva técnica si la rentabilidad esperada, calculada con los salarios actuales, es superior a la tasa de ganancia existente. Dada la técnica de producción, la acumulación de capital da lugar a un determinado crecimiento del producto y del empleo. A su vez, el crecimiento afecta a la distribución de los ingresos entre las ganancias y los salarios. Los diversos patrones de progreso técnico se caracterizan por presentar diferentes tendencias a largo plazo.

GRÁFICO 4

Relaciones de determinación en un modelo de crecimiento

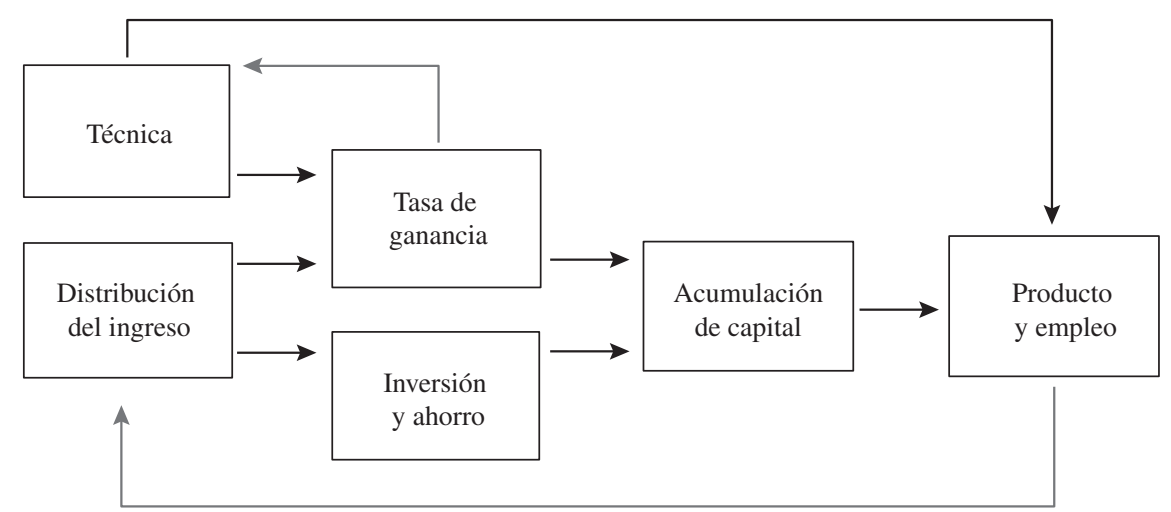

Fuente: elaboración propia sobre la base de G. Duménil y D. Lévy, “Technology and distribution: historical trajectories a la Marx”, Journal of Economic Behavior \& Organization, vol. 52, ํㅜㄹ, Amsterdam, Elsevier, 2003.

\section{III}

\section{El progreso técnico en la economía brasileña entre 1952 y 2008}

En el gráfico 5 se muestran las relaciones distribucióncrecimiento de la economía brasileña entre 1952 y 2008. Las productividades del trabajo y del capital se corrigieron para ese ciclo utilizando una regresión local, un método no paramétrico que estima curvas y superficies técnicas de suavizado (smoothing) (Loader, 1999). En el anexo se presenta la información sobre las fuentes del banco de datos y la metodología empleada para calcular las variables usadas en el artículo. Se puede observar un aumento de la productividad del trabajo y un declive de la productividad del capital a lo largo del período estudiado.
El patrón de progreso técnico fue un progreso sesgado en el sentido de Marx, ya que la productividad del trabajo creció un 2,25\% anual, mientras que la productividad del capital se redujo un 1,48\% anual entre 1952 y 2008.

No obstante, hubo tres fases diferentes en el dinamismo del progreso técnico en la economía brasileña (véase el gráfico 6). La primera corresponde al período que va de 1952 a 1975, cuando el crecimiento de la productividad del trabajo fue de un $4,45 \%$ y la productividad del capital se redujo un $1,93 \%$ anual. Esta fase correspondió a la "edad de oro" del desarrollo 
GRÁFICO 5

Brasil: relación distribución-crecimiento, 1952-2008

(En reales de 1995 por trabajador)

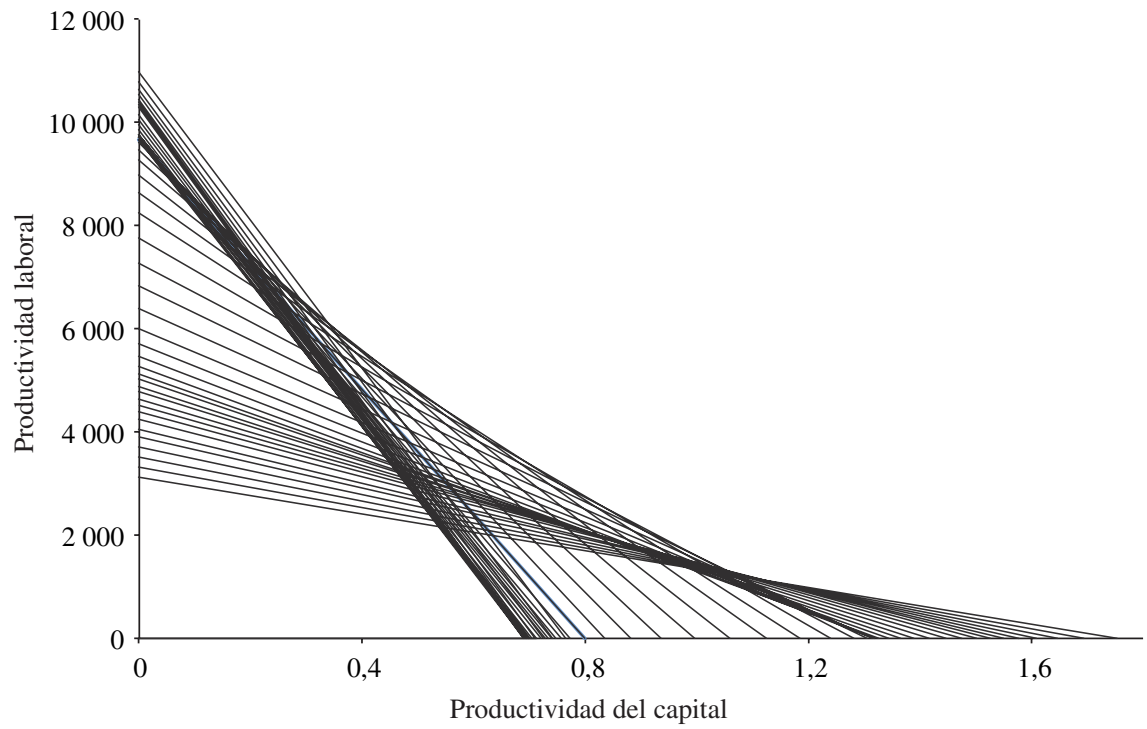

Fuente: Instituto Brasileño de Geografía y Estadística (IBGE), Sistema de Contas Nacionais - Brasil 2004/2008, Río de Janeiro, CD-Rom, 2010; Estatísticas do século XX, Río de Janeiro, CD-Rom, 2003; y Estatísticas históricas do Brasil: séries econômicas, demográficas e sociais de 1550 a 1988, Río de Janeiro, Fundação Instituto Brasileiro de Geografia e Estatística, 1990; A. Heston, R. Summers y B. Aten, "Penn World Table Version 6.2", Center for International Comparisons of Production, Income and Prices, 2006 [en línea] http://pwt.econ. upenn.edu8; A. Marquetti, "Estimativa do estoque de riqueza tangível no Brasil, 1950-1998”, Nova Economia, vol. 10, №2, Belo Horizonte, Universidad Federal de Minas Gerais, 2000.

GRÁFICO 6

Brasil: relación distribución-crecimiento y fases del progreso técnico: 1952-1975, 1975-1991, 1991-2008

(En reales de 1995 por trabajador)

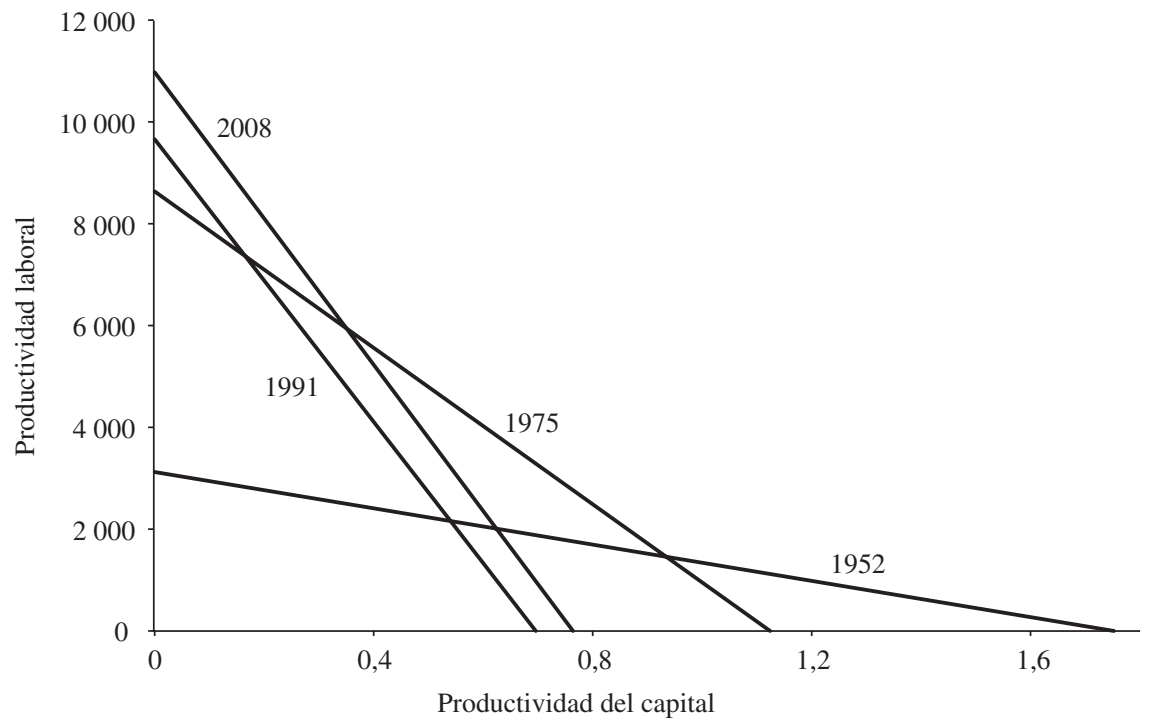

Fuente: Instituto Brasileño de Geografía y Estadística (IBGE), Sistema de Contas Nacionais - Brasil 2004/2008, Río de Janeiro, CD-Rom, 2010; Estatísticas do século XX, Río de Janeiro, CD-Rom, 2003; y Estatísticas históricas do Brasil: séries econômicas, demográficas e sociais de 1550 a 1988, Río de Janeiro, Fundação Instituto Brasileiro de Geografia e Estatística, 1990; A. Heston, R. Summers y B. Aten, "Penn World Table Version 6.2", Center for International Comparisons of Production, Income and Prices, 2006 [en línea] http://pwt.econ. upenn.edu8; A. Marquetti, "Estimativa do estoque de riqueza tangível no Brasil, 1950-1998", Nova Economia, vol. 10, № 2, Belo Horizonte, Universidad Federal de Minas Gerais, 2000. 
capitalista, cuando la economía brasileña se expandió a una tasa superior al 7\% anual. Durante ese período, el crecimiento económico fue liderado por el sector industrial a través del proceso de industrialización mediante sustitución de importaciones. La participación de la industria en el PIB a costo de factores pasó del 25\% en 1952 al 43,3\% en 1975.

Durante la segunda fase, entre 1975 y 1991, la productividad del trabajo creció un $0,71 \%$ anual y la caída de la productividad del capital fue de un 2,99\% anual. El Brasil sufrió las consecuencias del fin de la "edad de oro" y del declive de la productividad observado en varios países desarrollados en las décadas de 1970 y 1980 del siglo pasado. El ritmo de crecimiento económico se mantuvo elevado entre 1975 y 1980, debido al segundo Plan Nacional de Desarrollo (II PND). Este plan era una respuesta a la crisis internacional y tenía como objetivo estimular la producción de insumos básicos, bienes de capital y energía. La incapacidad del II PND para mantener el dinamismo del progreso técnico en la economía brasileña está en el origen de la crisis del modelo de industrialización mediante sustitución de importaciones. En la década de 1980, la tasa de crecimiento se redujo a un $2 \%$ anual. La participación de la industria en el PIB a costo de factores, después de alcanzar un máximo en 1985, se redujo al 36,6\% en 1991. Durante esta fase, se inició el proceso de des-industrialización de la economía brasileña.

Finalmente, durante la tercera fase, que comenzó en 1991 y terminó en 2008, las productividades del trabajo y del capital crecieron de forma anual un $0,75 \%$ y un $0,55 \%$, respectivamente. Se produjo un significativo cambio de la trayectoria de la productividad del capital, que pasó a aumentar como consecuencia de la adopción de las nuevas TIC. Esta fase representa un nuevo patrón de progreso técnico, denominado de cambio técnico ahorrador de insumos, en que el crecimiento de la productividad del trabajo es superior al de la productividad del capital y se produce un aumento de la relación capital-trabajo.

Al final de los años ochenta y al comienzo de los años noventa, la industrialización mediante sustitución de importaciones fue reemplazada por un nuevo modelo, acorde con el consenso de Washington (Williamson, 1992). Entre las reformas realizadas, cabe mencionar la adopción de una nueva forma de integración internacional, mediante la liberalización comercial y financiera y el inicio del proceso de privatizaciones. Como consecuencia, el Brasil comenzó a recibir un nuevo flujo de recursos externos, que permitieron lanzar el Plan Real en 1994.
El Plan Real vinculó el real con el dólar y tuvo gran éxito en la reducción de la tasa de inflación, que pasó del 1,996\% en 1993 al 8,3\% en 1997, en valores medidos según el deflactor del PIв. En el período comprendido entre 1991 y 2003, la economía brasileña creció un 2,7\% anual y un $4,5 \%$ anual entre 2003 y 2008 . A su vez, el porcentaje de la industria en el PIB a precios básicos se redujo a un $27,9 \%$.

Las tres fases del dinamismo del progreso técnico también pueden observarse en el gráfico 7 , en que se presenta la evolución de la productividad del trabajo en la economía brasileña entre 1952 y 2008. En el gráfico 7 se muestra un rápido crecimiento de la productividad del trabajo hasta mediados de los años setenta, seguido por un estancamiento hasta llegar a los años noventa, cuando la productividad laboral volvió a aumentar, aunque a tasas inferiores a las de la primera fase. Después de 2004, con un mayor crecimiento económico, hubo una rápida expansión de la productividad del trabajo, si bien se necesitan más datos para determinar en qué medida esa aceleración se debió a una nueva fase de dinamismo del progreso técnico o al ciclo económico.

En los resultados sobre la evolución del progreso técnico en la economía brasileña conviene resaltar dos aspectos significativos. En primer lugar, hay una correspondencia entre las diferentes fases del progreso técnico y el desempeño de la economía del Brasil. El patrón de progreso técnico sesgado en el sentido de Marx se produjo durante la industrialización mediante la sustitución de importaciones. En la literatura se señala que ese es el patrón típico en los países atrasados que fueron capaces de acercarse a los países líderes (Foley y Michl, 1999; Marquetti, 2003). En segundo lugar, las dos últimas fases del progreso técnico de la economía brasileña fueron similares a las observadas en los Estados Unidos de América (Duménil y Lévy, 2010). El cambio técnico se debe a un proceso histórico en el que un país puede inventar nuevos métodos de producción o beneficiarse de la transferencia de técnicas desarrolladas en otros países. Generalmente, los países de industrialización tardía adoptan las técnicas desarrolladas en el país central. Las nuevas técnicas no son un bien público y, por lo tanto, suponen un costo de adquisición y tardan en ser implementadas en los países menos desarrollados. Además, requieren el acceso a máquinas y equipos, educación de la fuerza de trabajo y un período de aprendizaje por parte de las compañías y los trabajadores. Sin embargo, utilizar técnicas desarrolladas en el país líder es relativamente más fácil y rápido que descubrir nuevas técnicas. 


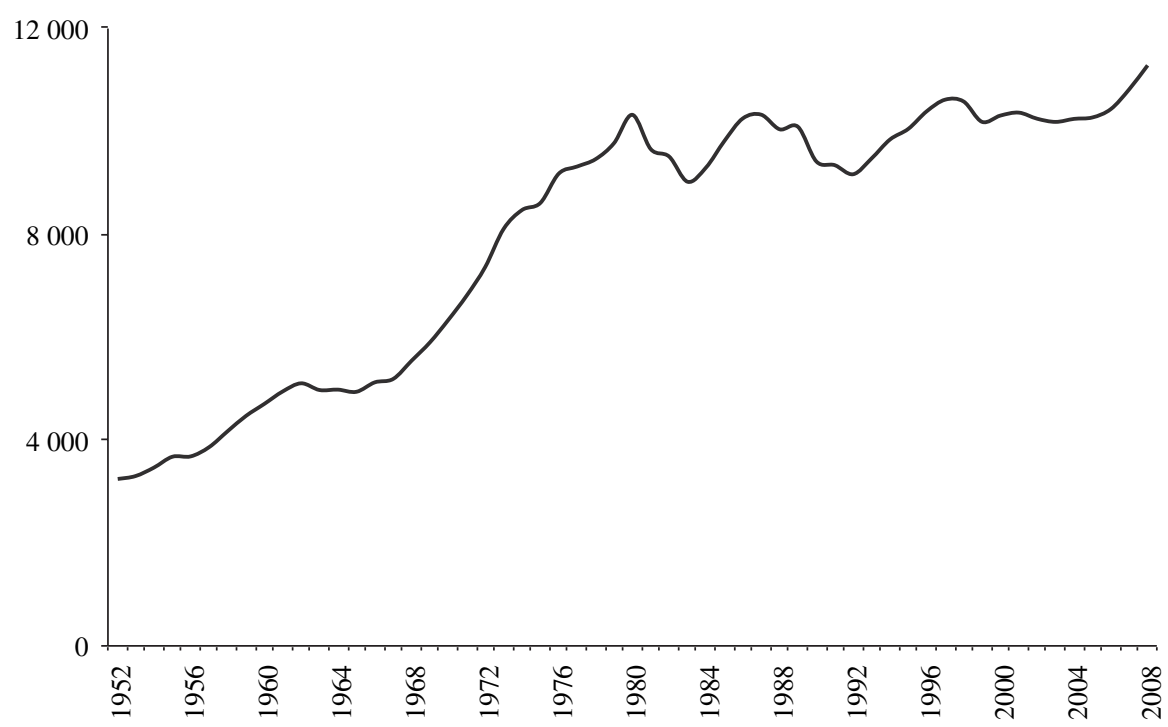

Fuente: Instituto Brasileño de Geografía y Estadística (IBGE), Sistema de Contas Nacionais - Brasil 2004/2008, Río de Janeiro, CD-Rom, 2010; Estatísticas do século XX, Río de Janeiro, CD-Rom, 2003; y Estatísticas históricas do Brasil: séries econômicas, demográficas e sociais de 1550 a 1988, Río de Janeiro, Fundação Instituto Brasileiro de Geografia e Estatística, 1990; A. Heston, R. Summers y B. Aten, "Penn World Table Version 6.2”, Center for International Comparisons of Production, Income and Prices, 2006 [en línea] http://pwt.econ. upenn.edu8; A. Marquetti, "Estimativa do estoque de riqueza tangível no Brasil, 1950-1998”, Nova Economia, vol. 10, №2, Belo Horizonte, Universidad Federal de Minas Gerais, 2000.

\section{IV}

\section{Rentabilidad, distribución y progreso técnico}

Según un enfoque marxista clásico, la búsqueda de ganancias constituye el principal impulso del progreso técnico. De acuerdo con este enfoque, los capitalistas individuales adoptan cambios técnicos que reducen los costos de producción, manteniendo los precios y los salarios reales existentes, a fin de obtener una tasa de ganancia por sobre el promedio al vender sus productos a precios determinados por competidores con menor eficiencia técnica. Sin embargo, es la disputa entre el capital y el trabajo con respecto a la distribución del valor agregado la que determina la forma que tomará el progreso técnico en la sociedad capitalista. La mecanización sustituye el trabajo humano por las máquinas y equipos en el proceso productivo, aumentando la productividad laboral. Okishio (1961) demostró que, si el salario real permanece constante, la tasa de ganancia tiende a acrecentarse aunque el progreso técnico tome la forma de progreso sesgado en el sentido de Marx.
La tasa de ganancia se mide por la relación entre el total de las ganancias generadas en un período y el capital fijo adelantado en el proceso productivo. Conviene recordar que solo una parte del total de las ganancias es apropiada por los capitalistas. Otras partes de la plusvalía son apropiadas por los trabajadores no productivos, por el Estado y por la transferencia internacional de valor. Duménil y Lévy (1993) analizan las distintas formas de calcular la tasa de ganancia.

En el presente estudio, la tasa de ganancia se ha calculado de la siguiente manera:

$$
v=Z / K=(Z / X) /(K / X)=\pi p=(1-w / x) p
$$

donde $\pi$ es la parte correspondiente a las ganancias, $p$ es la productividad del capital, $w$ es el salario medio real y $x$ es la productividad del trabajo. El salario medio real se deflacta según el deflactor del PIB y representa el costo 
del trabajador desde el punto de vista del capitalista. La evolución de la tasa de ganancia depende de dos factores: la distribución funcional de los ingresos y la productividad del capital. A su vez, la distribución funcional de los ingresos está determinada por la evolución del salario medio real en relación con la productividad del trabajo. La parte correspondiente a las ganancias aumenta y, por lo tanto, también lo hace la tasa de ganancia cuando el crecimiento de la productividad del trabajo es superior al incremento del salario medio.

En el gráfico 8 se observa la evolución en la economía brasileña de la tasa neta de ganancia medida a precios corrientes y a precios constantes de 1995 , durante el período estudiado. Se advierte una tendencia a la baja de ambas medidas entre 1952 y el comienzo de la década de 1990, cuando se produjo un leve aumento de la rentabilidad. El período 1952-1990 puede dividirse en dos etapas. En la primera, entre 1952 y 1973, se produjo un rápido proceso de industrialización en los años cincuenta, seguido de disputas políticas al comienzo de los años sesenta que culminaron en el golpe militar de 1964. Los cambios políticos y económicos ocurridos con la dictadura militar explican en parte el incremento de la tasa de ganancia desde mediados de los años sesenta hasta 1973. En la segunda etapa, de 1973 a 1990, dicha tasa decreció fuertemente y la caída de la rentabilidad fue uno de los factores determinantes de la crisis estructural de la economía brasileña. Este período se caracterizó por el segundo Plan Nacional de Desarrollo, con una rápida acumulación de capital y de deuda externa, que culminó en la crisis de la deuda, la elevada inflación y las bajas tasas de crecimiento de la década de 1980.

Entre 1990 y 2008, tuvo lugar un ligero incremento de la tasa de ganancia. Esa fase corresponde al período de neoliberalismo de la economía brasileña entre 1990 y 2003, seguido por un período en que se combinaron unas condiciones internacionales favorables para el país con la recuperación del papel del Estado en la formulación y ejecución de políticas de desarrollo entre 2003 y 2008.

Los cambios de la tasa de ganancia se explican por las modificaciones en la distribución funcional de los ingresos o en la productividad del capital. En el gráfico 9.A se constata que la parte correspondiente a las ganancias se mantuvo relativamente estable a lo largo del período estudiado, con un promedio del $57,8 \%$ del PIB. La distribución funcional de los ingresos favoreció a los trabajadores en los períodos de mayor agitación política, como el final de la década de 1950 y el inicio de

GRÁFICO 8

Brasil: tasa neta de ganancia, 1952-2008

(En porcentajes)

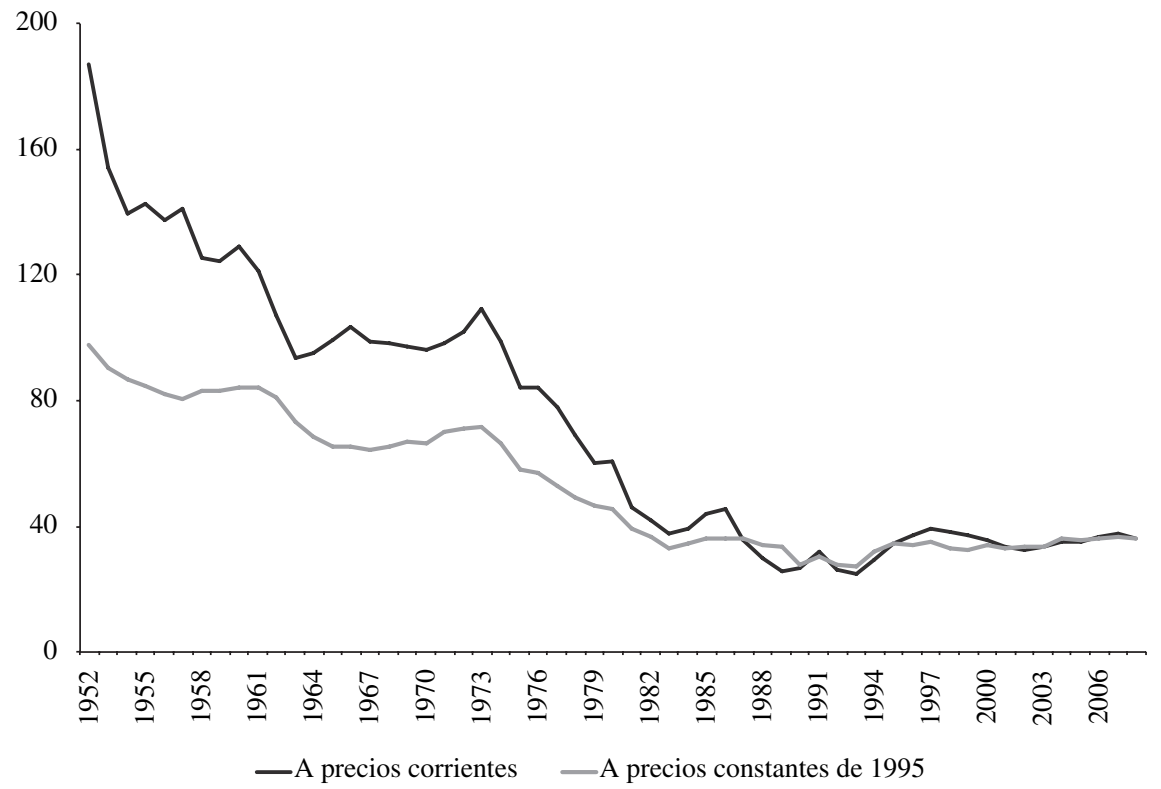

Fuente: Instituto Brasileño de Geografía y Estadística (IBGE), Sistema de Contas Nacionais - Brasil 2004/2008, Río de Janeiro, CD-Rom, 2010; Estatísticas do século XX, Río de Janeiro, CD-Rom, 2003; y Estatísticas históricas do Brasil: séries econômicas, demográficas e sociais de 1550 a 1988, Río de Janeiro, Fundação Instituto Brasileiro de Geografia e Estatística, 1990; A. Marquetti, "Estimativa do estoque de riqueza tangível no Brasil, 1950-1998", Nova Economia, vol. 10, №2, Belo Horizonte, Universidad Federal de Minas Gerais, 2000. 
los años sesenta, así como durante la apertura política de la segunda mitad de los años setenta y el comienzo de los años ochenta y los años de mayor inflación, sobre todo el final de la década de 1980 y el inicio de la de 1990.

Por otra parte, se produjo una disminución de los salarios después de la dictadura militar en 1964, hasta el llamado milagro brasileño (1968-1973). Con posterioridad a 1993, cuando la participación correspondiente a las ganancias alcanzó el mínimo del 50,5\% del PIB, tuvo lugar un rápido aumento de la participación de las ganancias en la renta nacional, que alcanzó su máximo del 60,7\% en 2004. Este cambio se relaciona aparentemente con el efecto de las reformas neoliberales y las políticas macroeconómicas relativas al empleo y a los salarios, que reforzaron el poder político de la clase capitalista. En el gráfico 9.B se revela que el salario medio real evolucionó de acuerdo con la productividad del trabajo, excepto durante el período 1991-2004.

En el gráfico 10 se presenta la evolución de la productividad del capital, medida a precios constantes de 1995 y a precios corrientes. De modo similar a lo observado con respecto a la tasa de ganancia, hubo tres fases en el progreso de la productividad del capital: una fase de leve declive de 1952 a 1973, seguida de una rápida caída entre 1973 y 1990 y de un aumento moderado entre 1990 y 2008. Sin embargo, la magnitud de la productividad del capital en 2008 era similar a la existente al comienzo de los años ochenta. La tercera fase representa un cambio a largo plazo en la evolución de la productividad del capital en el Brasil, que podría reflejar la adopción de innovaciones vinculadas a las TIC. Se observa que la evolución a largo plazo de la tasa de ganancia está principalmente determinada por la evolución de la productividad del capital, que es un factor tecnológico.

La diferencia entre la tasa neta de ganancias medida a precios corrientes y a precios constantes se debe al crecimiento del deflactor de precios de los bienes de inversión en relación con el deflactor de precios del PIB, que se muestra en el gráfico 11. Durante los años cincuenta y el inicio de los años sesenta se produjo un incremento de este índice, seguido por un período de estabilidad hasta fines de la década de 1970, cuando volvieron a aumentar los precios relativos de los bienes de capital, que alcanzaron su valor máximo a fines de los años ochenta. Al comienzo de la década de 1990, el precio relativo de los bienes de capital en la economía brasileña alcanzó una estabilidad que perduró hasta 2008.

GRÁFICO 9

Brasil: ganancia y evolución de la productividad del trabajo y del salario real, 1952-2008

A. Ganancia, 1952-2008

(En porcentajes del producto interno bruto (PIB))

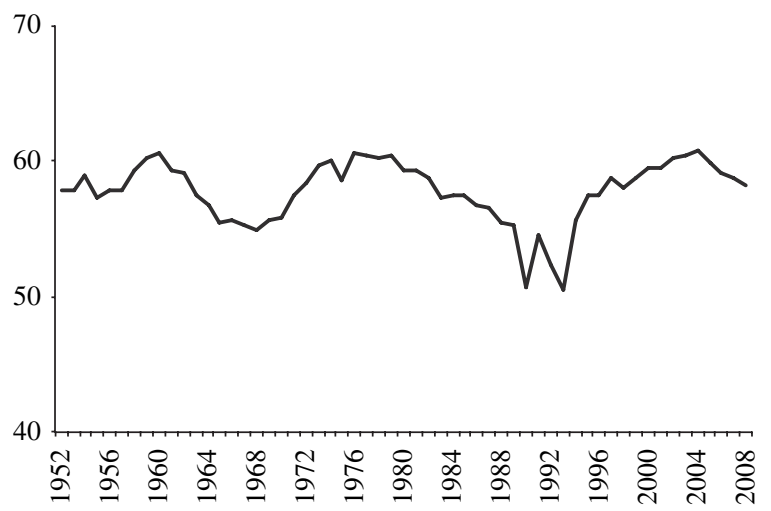

B. Productividad del trabajo y salario real, 1952-2008 (En porcentajes)

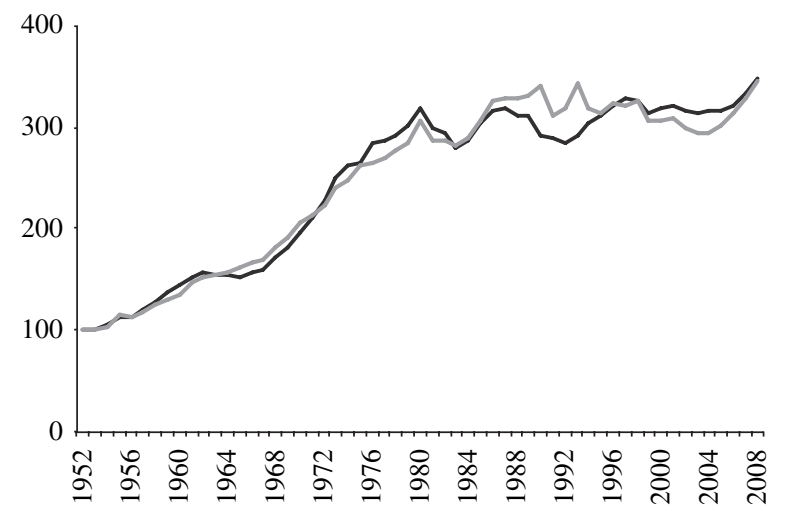

Productividad del trabajo

Fuente: Instituto Brasileño de Geografía y Estadística (IBGE), Sistema de Contas Nacionais - Brasil 2004/2008, Río de Janeiro, CD-Rom, 2010; Estatísticas do século XX, Río de Janeiro, CD-Rom, 2003; y Estatísticas históricas do Brasil: séries econômicas, demográficas e sociais de 1550 a 1988, Río de Janeiro, Fundação Instituto Brasileiro de Geografia e Estatística, 1990; A. Heston, R. Summers y B. Aten, "Penn World Table Version 6.2", Center for International Comparisons of Production, Income and Prices, 2006 [en línea] http://pwt.econ.upenn.edu8. 
GRÁFICO 10

Brasil: productividad del capital, 1952-2008

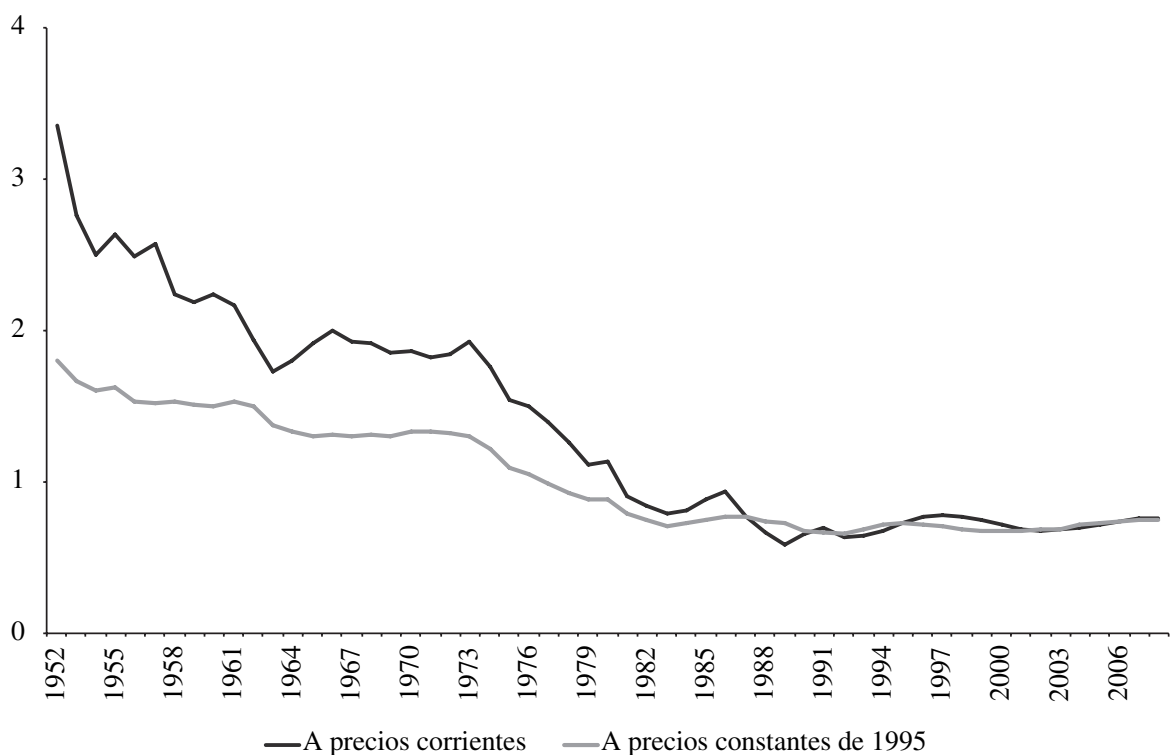

Fuente: Instituto Brasileño de Geografía y Estadística (IBGE), Sistema de Contas Nacionais - Brasil 2004/2008, Río de Janeiro, CD-Rom, 2010; Estatísticas do século XX, Río de Janeiro, CD-Rom, 2003; y Estatísticas históricas do Brasil: séries econômicas, demográficas e sociais de 1550 a 1988, Río de Janeiro, Fundação Instituto Brasileiro de Geografia e Estatística, 1990; A. Marquetti, "Estimativa do estoque de riqueza tangível no Brasil, 1950-1998”, Nova Economia, vol. 10, № 2, Belo Horizonte, Universidad Federal de Minas Gerais, 2000.

GRÁFICO 11

Brasil: precio de los bienes de capital en relación con el deflactor del PIB, 1952-2008 (En porcentajes)

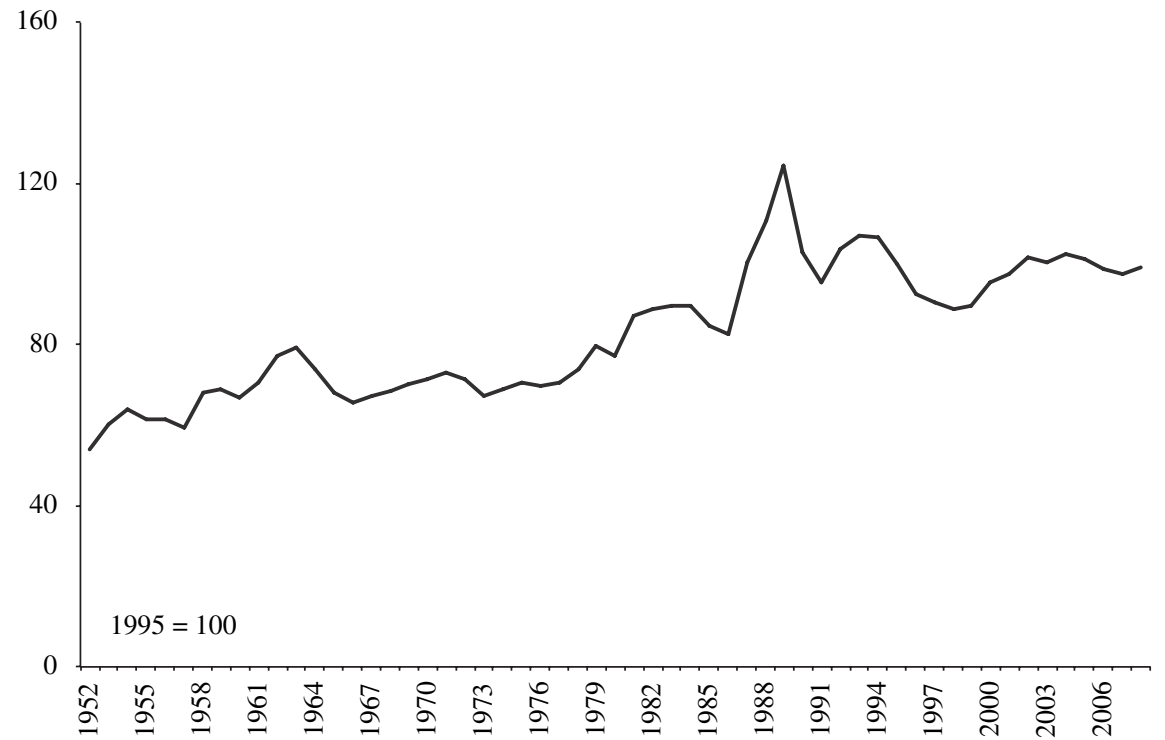

Fuente: Instituto Brasileño de Geografía y Estadística (IBGE), Sistema de Contas Nacionais - Brasil 2004/2008, Río de Janeiro, CD-Rom, 2010; Estatísticas do século XX, Río de Janeiro, CD-Rom, 2003; y Estatísticas históricas do Brasil: séries econômicas, demográficas e sociais de 1550 a 1988, Río de Janeiro, Fundação Instituto Brasileiro de Geografia e Estatística, 1990; A. Marquetti, "Estimativa do estoque de riqueza tangível no Brasil, 1950-1998", Nova Economia, vol. 10, №2, Belo Horizonte, Universidad Federal de Minas Gerais, 2000. 


\section{Acumulación de capital y progreso técnico}

La acumulación de capital mide la velocidad con que el país engrosa su masa de capital productivo, que está compuesta por edificaciones no residenciales, máquinas y equipos. Por lo tanto, mientras haya disponibilidad de mano de obra, la acumulación de capital mide la velocidad con que se expande la capacidad del país de producir riquezas. La tasa neta de acumulación de capital está determinada por la tasa de ganancia y por la tasa de inversión. Si el patrón de progreso técnico es sesgado en el sentido de Marx, la tendencia de la tasa de acumulación debería ser a la baja, en consonancia con el declive de la tasa de ganancia.

En el gráfico 12 se presenta la tasa de acumulación de capital de la economía brasileña entre 1952 y 2008. Se observan tres aspectos significativos con respecto a la acumulación de capital en el Brasil. En primer lugar, se pueden diferenciar cinco ciclos en el período estudiado, a saber: 1955-1965 con un máximo en 1959; 1965-1983 con un máximo en 1975; 1983-1993 con un máximo en 1986; 1993-2003 con un máximo en 1997 y, finalmente, el ciclo actual, que se inició en 2003. En segundo lugar, la tasa neta de acumulación ha experimentado una tendencia a la baja similar a la observada en la tasa neta de ganancia, como consecuencia del patrón de progreso técnico sesgado en el sentido de Marx. Los máximos, con la excepción del correspondiente a 1975, y los valles de los ciclos se producen en valores inferiores a los de los máximos y valles precedentes. En tercer lugar, se pueden diferenciar dos períodos muy distintos en la tasa de acumulación de capital en el Brasil. Entre 1952 y el final de los años setenta, el crecimiento económico fue liderado por el sector industrial, a través de un modelo de industrialización mediante sustitución de importaciones. Durante ese período tuvo lugar un proceso de mecanización de la economía brasileña. En la segunda mitad de los años setenta y a comienzos de los años ochenta se produjo una acentuada caída de la tasa de ganancia, que marcó la transición entre la etapa con una alta tasa de acumulación de capital en la economía del Brasil y la etapa con una tasa más moderada. Desde

GRÁFICO 12

Brasil: tasa neta de acumulación de capital, 1952-2008

(En porcentajes)

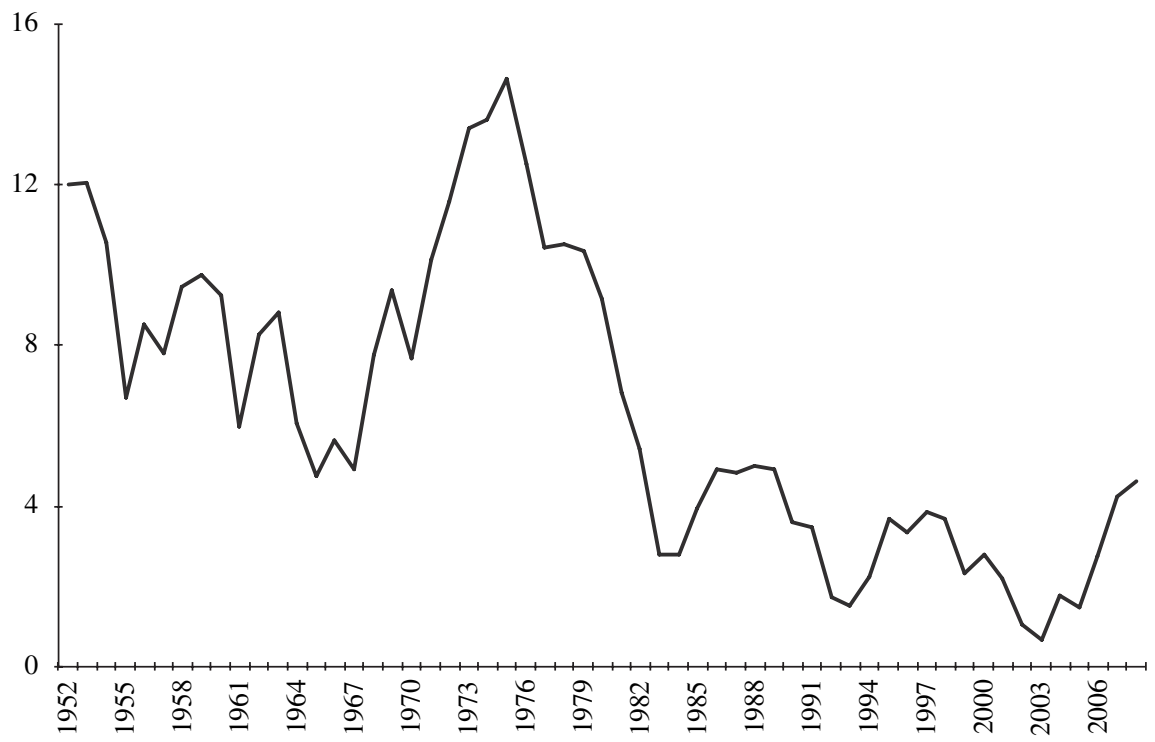

Fuente: Instituto Brasileño de Geografía y Estadística (IBGE), Sistema de Contas Nacionais - Brasil 2004/2008, Río de Janeiro, CD-Rom, 2010; Estatísticas do século XX, Río de Janeiro, CD-Rom, 2003; y Estatísticas históricas do Brasil: séries econômicas, demográficas e sociais de 1550 a 1988, Río de Janeiro, Fundação Instituto Brasileiro de Geografia e Estatística, 1990; A. Marquetti, "Estimativa do estoque de riqueza tangível no Brasil, 1950-1998”, Nova Economia, vol. 10, № 2, Belo Horizonte, Universidad Federal de Minas Gerais, 2000. 
comienzos de los años ochenta hasta el inicio de los años noventa, la baja tasa de acumulación obedeció a la combinación de una escasa rentabilidad y la crisis de la deuda externa. Desde inicios de la década de 1990 hasta 2003, en el Brasil se adoptó el modelo neoliberal, pero - a pesar del aumento de la rentabilidad- se observó una exigua tasa de acumulación, debido a la caída de la tasa de inversión.

En el gráfico 13 se aprecia la evolución de la tasa de acumulación de capital y de la tasa neta de ganancia entre 1952 y 2008 . La tendencia a la baja de la tasa de acumulación fue similar a la observada en la tasa neta de ganancia, lo que indica que existe una relación a largo plazo entre esas dos variables. La disminución de la rentabilidad provocada por el declive de la productividad del capital fue uno de los factores responsables de la caída de la tasa de acumulación en la economía brasileña. Como se ha indicado anteriormente, se trata de las tendencias a largo plazo en el patrón de progreso técnico sesgado en el sentido de Marx.

La evolución de la tasa de acumulación de capital y de la tasa neta de inversión se muestra en el gráfico 14. Los cambios cíclicos de la tasa de acumulación de capital se ven marcadamente influidos por la tasa neta de inversión. El Plan de Metas, que supuso a partir de 1956 un gran incremento de las inversiones liderado por el sector público y las empresas estatales y con alta participación de capitales externos, dio lugar a una rápida expansión de las inversiones hasta el final de la década.

El inicio de los años sesenta fue un período de gran agitación política, que culminó con el golpe militar de 1964. Después de una serie de cambios institucionales, se produjo una recuperación de las inversiones a fines de los años sesenta. La tasa neta de acumulación experimentó un robusto crecimiento durante el llamado milagro económico brasileño, entre 1968 y 1973, y superó el 12\% anual entre 1974 y 1976. Conviene resaltar que la tasa de inversión alcanzó su máximo histórico durante el II PND, un período de acentuada caída de la rentabilidad. El elevado nivel de inversiones se debió al liderazgo del sector estatal en el proceso, que fue financiado mediante el endeudamiento externo.

Los años ochenta se caracterizaron por el declive de la tasa neta de inversión, que continuó durante los años noventa y el inicio de la década de 2000. Esta tasa alcanzó su mínimo en 2003 y después volvió a crecer.

La reducción de la tasa de acumulación en la economía brasileña en 1975 se explica por la pronunciada caída de la tasa de ganancia que se produjo después de 1973. En los años ochenta, la tasa de acumulación también comenzó a sufrir los efectos negativos de la reducción

GRÁFICO 13

Brasil: tasa neta de acumulación de capital y tasa neta de ganancia, 1952-2008 (En porcentajes)

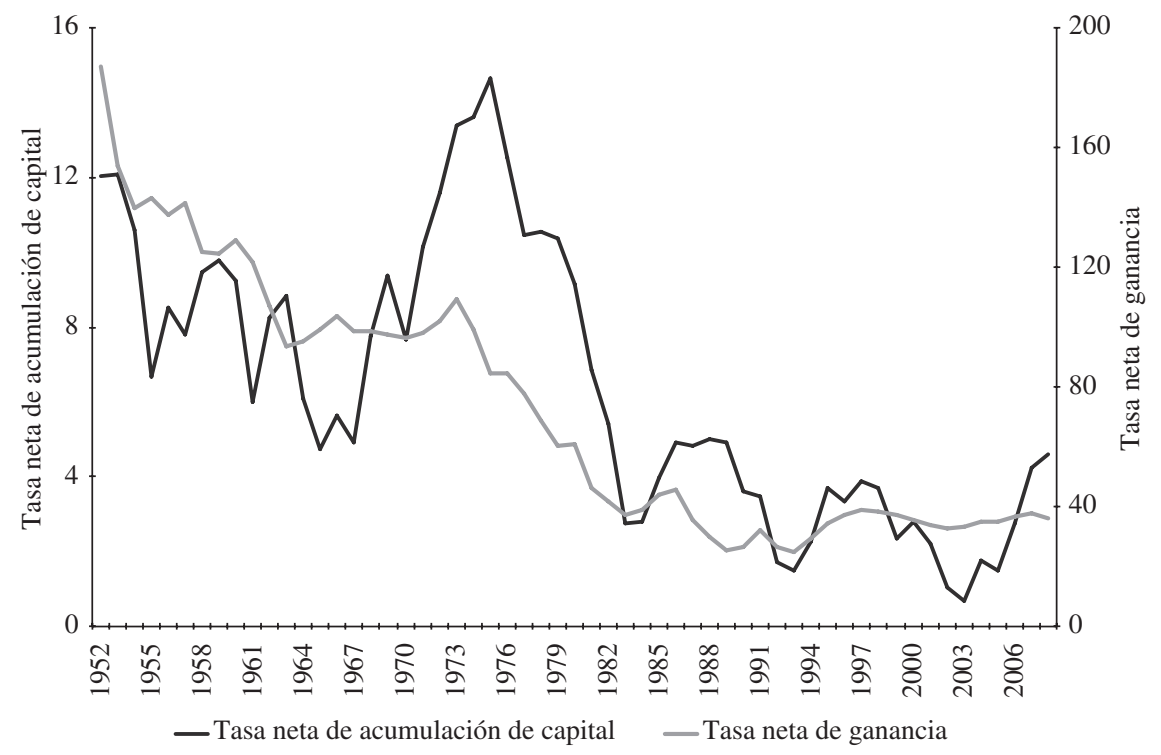

Fuente: Instituto Brasileño de Geografía y Estadística (IBGE), Sistema de Contas Nacionais - Brasil 2004/2008, Río de Janeiro, CD-Rom, 2010; Estatísticas do século XX, Río de Janeiro, CD-Rom, 2003; y Estatísticas históricas do Brasil: séries econômicas, demográficas e sociais de 1550 a 1988, Río de Janeiro, Fundação Instituto Brasileiro de Geografia e Estatística, 1990; A. Marquetti, "Estimativa do estoque de riqueza tangível no Brasil, 1950-1998", Nova Economia, vol. 10, № 2, Belo Horizonte, Universidad Federal de Minas Gerais, 2000. 


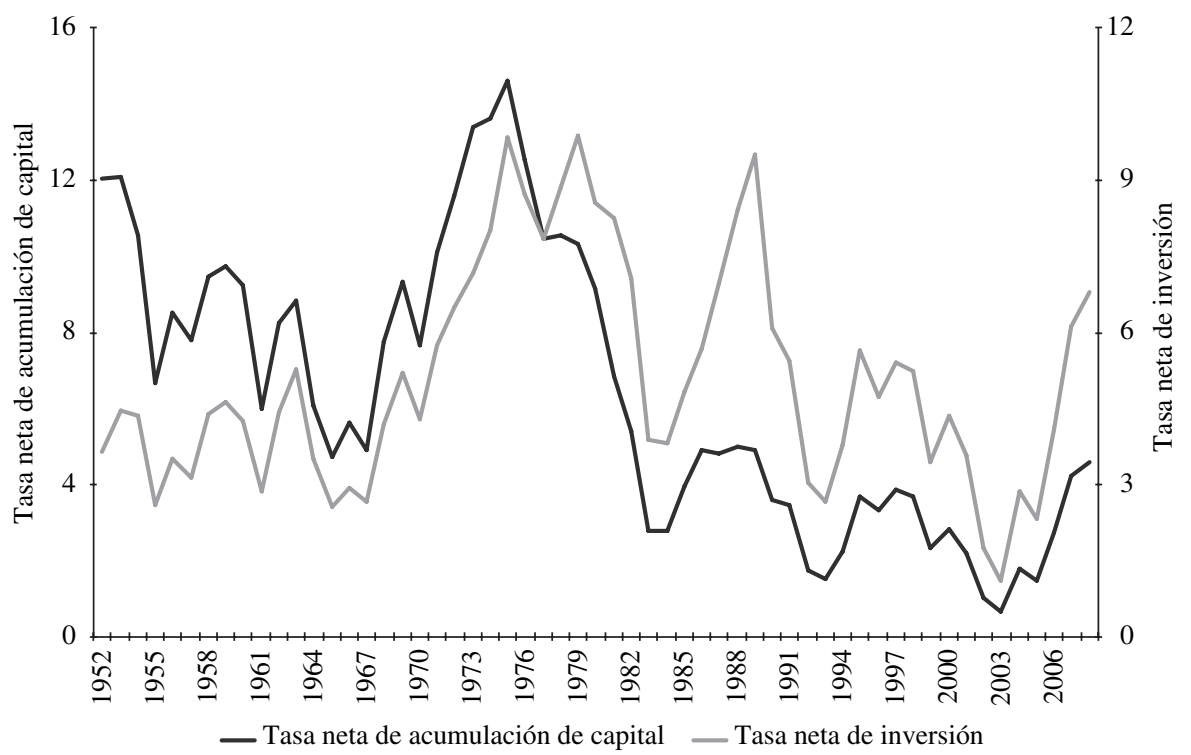

Fuente: Instituto Brasileño de Geografía y Estadística (IBGE), Sistema de Contas Nacionais - Brasil 2004/2008, Río de Janeiro, CD-Rom, 2010; Estatísticas do século XX, Río de Janeiro, CD-Rom, 2003; y Estatísticas históricas do Brasil: séries econômicas, demográficas e sociais de 1550 a 1988, Río de Janeiro, Fundação Instituto Brasileiro de Geografia e Estatística, 1990; A. Marquetti, "Estimativa do estoque de riqueza tangível no Brasil, 1950-1998", Nova Economia, vol. 10, N2 2, Belo Horizonte, Universidad Federal de Minas Gerais, 2000.

de la tasa de inversión. La estrategia adoptada con el II PND provocó el incremento de la deuda externa y, por lo tanto, agudizó la fragilidad financiera del país. Los efectos de la segunda crisis del petróleo y, principalmente, del aumento de las tasas de interés en el mercado internacional fueron muy perjudiciales para la economía brasileña. La capacidad de generar riqueza, medida por la tasa de crecimiento de la productividad del trabajo y necesaria para hacer frente a los futuros pagos, apenas se acrecentó en relación con el incremento de la deuda externa y de la probabilidad de que se produjeran choques externos negativos. El servicio de dicha deuda significó una transferencia enorme de recursos al extranjero en los años ochenta y provocó el decrecimiento de la tasa neta de inversión.

Por otra parte, el abultamiento de la deuda interna, de la tasa real de interés en el mercado interno y de la tasa de inflación vinculada al mecanismo de indexación involucró una transferencia de recursos del sector productivo al sector financiero. Estos factores, junto con la caída de la tasa de ganancia, explican la reducción de la tasa de acumulación observada en la economía brasileña desde finales de los años setenta. El origen de la crisis económica brasileña radica en la disminución del dinamismo del progreso técnico a mediados de la década de 1970. La merma de la tasa neta de inversión a partir de finales de los años setenta agravó la situación, que ya tendía a producir un declive de la tasa de acumulación.

En este estudio se refrenda el análisis de las causas de la inflación brasileña a finales de los años setenta y comienzo de la década de 1980 que realizó Celso Furtado en 1983. Según este autor:

[...] la raíz de la inflación brasileña está en la reducción de la productividad del sistema económico [...] La productividad de las inversiones ha sido tradicionalmente muy alta entre nosotros. Para obtener el aumento de un uno por ciento del Producto Interno, solo se necesitaba invertir un dos por ciento de ese mismo producto [...] Lo que se observa actualmente es una formidable disminución de la productividad. Para lograr un incremento del uno por ciento del producto, se necesita invertir entre el cuatro y el seis por ciento de este [...] la causa principal está en la desarticulación de las inversiones públicas y de las inversiones privadas inducidas por ellas. (Furtado, 1983, págs. 21-22). Es interesante observar que, a lo largo de los años noventa, se mantuvo la tendencia a la baja de la tasa de acumulación de capital y de la tasa neta de inversión, a pesar del aumento de la rentabilidad. Los años ochenta, la llamada década perdida, constituyeron un período de crisis y de transición del modelo de industrialización 
mediante sustitución de importaciones al modelo neoliberal. El neoliberalismo representó la adopción de un modelo de crecimiento "amigable con el mercado", en el que se redujo el papel del Estado en la economía, se privatizaron empresas estatales, se flexibilizaron los mercados de capitales y del trabajo y se produjo una mayor integración internacional. Los que propusieron este modelo consideraban que, mediante las reformas neoliberales, el Brasil se beneficiaría del proceso de globalización y recibiría un nuevo flujo de inversiones internacionales, que incrementaría la acumulación de capital y la productividad de la economía (Franco, 1998).

A partir de 1990, la economía brasileña pasó por una serie de reformas neoliberales. Entre ellas, se encontraban la adopción de una nueva forma de integración internacional mediante la liberalización comercial y financiera (Cysne, 1998) y el programa de privatizaciones, con la venta de las empresas de los sectores petroquímico y de minerales metálicos. La renegociación de la deuda externa en el contexto del Plan Brady permitió que el Brasil volviera al mercado financiero internacional y acumulase reservas suficientes para el lanzamiento del Plan Real en 1994. El Plan comprendía dos partes: una política macroeconómica para controlar la inflación y un programa de reformas neoliberales para estimular el crecimiento.

La alta tasa de interés y el regreso del Brasil al mercado internacional de capitales permitieron que tuviera lugar una apreciación del tipo de cambio y se redujera la tasa de inflación a valores inferiores a un dígito. Después de 1994, comenzaron las privatizaciones de los servicios públicos, con la venta de las empresas de telecomunicaciones, eléctricas y bancarias.

Uno de los principales problemas del Plan Real fue el aumento de la fragilidad financiera externa de la economía brasileña, que — asociada a la volatilidad de los capitales internacionales- provocó la depreciación del real a comienzos de 1999. La crisis brasileña fue precedida por una serie de crisis internacionales que habían comenzado con la crisis de México en 1994, seguida por la crisis asiática en 1997 y la crisis de la Federación de Rusia en 1998. Las autoridades económicas del país respondieron a la crisis adoptando una política en que se combinaban una meta para la inflación, un superávit fiscal primario y un tipo de cambio fluctuante. La política monetaria desempeñó un papel fundamental para controlar el tipo de cambio a través de una elevada tasa de interés capaz de atraer capitales internacionales y, de ese modo, mantener la tasa de inflación en valores próximos a los deseados.

Con el Plan Real, el Brasil adoptó plenamente la agenda neoliberal. Aunque las políticas tuvieron éxito en reducir la inflación, fueron incapaces de devolver el dinamismo a la economía brasileña. Hubo una tasa neta de acumulación muy baja, a pesar del cambio del patrón de progreso técnico de la economía brasileña, lo que dio lugar a una limitada recuperación de la rentabilidad. La tasa neta de inversión, después de una recuperación entre 1993 y 1997, volvió a caer y alcanzó el valor mínimo de la serie en 2003.

A partir de 2004, se produjo una recuperación de la tasa neta de inversión y de la tasa de acumulación. La cuestión fundamental es si la recuperación representó un cambio cíclico o una ruptura con el período de bajo crecimiento de la economía brasileña entre 1980 y 2003. Inicialmente, el país se benefició del aumento de las exportaciones gracias a la expansión de las ventas internacionales de productos básicos a China y la India. Sin embargo, en un segundo momento, hubo una pronunciada expansión de las inversiones gracias al Programa de Aceleración del Crecimiento (PAC). El PAC es un programa cuyo objetivo principal es estimular el crecimiento económico del país y que prevé que el Estado actúe como promotor e inductor de las inversiones del sector público, las empresas estatales y las empresas privadas. La tasa neta de inversión y la tasa de acumulación de capital en 2007 y 2008 fueron las mayores desde 1990.

\section{VI}

\section{Consideraciones finales}

El análisis del progreso técnico en la economía brasileña reveló que el patrón sesgado en el sentido de Marx, ahorrador de trabajo y consumidor de capital, fue predominante en el período comprendido entre 1952 y 2008. Como la distribución funcional del ingreso fue relativamente estable, se produjo una caída de la tasa de ganancia en la economía del Brasil en el período estudiado. 
Sin embargo, ese patrón no estuvo presente de manera uniforme en los años estudiados. Se pueden distinguir tres fases de progreso técnico, a saber: 1952-1975; 1975-1991, y 1991-2008. La primera fase corresponde al auge de la estrategia de industrialización mediante sustitución de importaciones, con un rápido crecimiento de la economía brasileña, un aumento anual de la productividad del trabajo del $4,45 \%$ y una reducción anual de la productividad del capital del $1,93 \%$. Durante la segunda fase, marcada por la crisis y el fin del proceso de sustitución de importaciones, se produjo una aguda caída de la tasa de ganancia y de la acumulación de capital. La productividad del trabajo solo aumentó un $0,71 \%$ anual y la productividad del capital disminuyó un 3\% anual. Finalmente, la tercera fase supuso un nuevo patrón de progreso técnico, sobre todo en lo referente al incremento de la productividad del capital. La productividad laboral creció un $0,75 \%$ anual y la del capital registró un incremento del $0,55 \%$ anual.

La crisis brasileña a partir de mediados de la década de 1970 reprodujo una situación que ya se había verificado en las economías desarrolladas y que conllevó un pronunciado declive de la productividad del capital y el estancamiento de la productividad del trabajo en esos países. La caída de la tasa de ganancia en la economía brasileña a partir de 1973 dio lugar al decrecimiento de la tasa de acumulación de capital y, por lo tanto, de la capacidad de la economía del Brasil para lograr aumentos significativos de la productividad del trabajo. La crisis de la deuda en los años ochenta agravó el menoscabo de la tasa de acumulación y la escasa capacidad de crecimiento de la economía brasileña. A partir de finales de la década de 1970, se produjo también una acentuada caída de la tasa neta de inversión.

Durante los años noventa, el crecimiento de la economía brasileña fue moderado, a pesar de las posibilidades que suponían el mayor dinamismo del progreso técnico — asociado a las nuevas TIC — y el incremento de la tasa de ganancia. Este aumento debería haber estado acompañado de un acrecentamiento de la inversión, pero no fue así. La inversión no se expandió de forma consistente hasta la implementación del PAC. La productividad del trabajo creció un $2 \%$ anual y la del capital un $1,9 \%$ anual entre 2003 y 2008. Cuando las condiciones relativas a la oferta son adecuadas, las políticas de inspiración keynesiana pueden estimular un mayor crecimiento económico y un incremento de la productividad.

ANEXO

Banco de datos y metodología

En este apéndice se presentan las fuentes de información y el procedimiento utilizado para formar el banco de datos empleado en este artículo. El principal problema para desarrollar trabajos empíricos sobre la economía brasileña a largo plazo es organizar la información de manera consistente. En el Brasil, las cuentas nacionales se comenzaron a publicar en 1947. La última gran modificación metodológica del Sistema de Cuentas Nacionales tuvo lugar con la publicación del Sistema de Contas Nacionais - Brasil, Referência 2000. Los cambios se realizaron para aproximarse a las recomendaciones del Sistema de Cuentas Nacionales 1993. En el futuro, deberá producirse una nueva modificación para que las cuentas nacionales del país se adapten al Sistema de Cuentas Nacionales 2008.

Los datos del PIB real y del deflactor del PIB se obtuvieron de IBGE (1990) y de IBGE (2003) para el período 1952-1985. En el caso del período 19952008, los datos se tomaron de IBGE (2010). Debido a las modificaciones metodológicas, el PIB de 1995 es un $8,84 \%$ mayor en IBGE (2010) que en IBGE (2003).
Los datos para el período 1986-1994 se calcularon utilizando las tasas de crecimiento del PIB real tomadas de IBGE (2003) y aumentándolas según una distribución de ese $8,84 \%$ a lo largo del período. Así, la fuente de datos para el PIB real de 1985 es IBGE (2003) y para 1995 es IBGE (2010). El ajuste de las diferencias entre las series se lleva a cabo a lo largo del período 1986-1994. Para las demás variables, se utilizó un procedimiento similar.

El número de trabajadores para la etapa comprendida entre 1995 y 2008 se calculó sobre la base de IBGE (2010). También se tomaron de IBGE (1990) los datos de los años censales. La información necesaria para completar los años sin datos se tomó de Heston, Summers y Atten (2006). Es necesario resaltar que en IBGE (2003) se presenta el número de trabajadores para los años comprendidos entre 1990 y 1995.

Los datos sobre los salarios y la remuneración de los trabajadores en el período 1995-2008 se obtuvieron de IBGE (2010) y, en el caso de los años censales, de IBGE (2010). El rendimiento mixto está dividido en dos 
partes, una que se suma a los salarios y otra al excedente operacional. En cuanto a los años respecto de los cuales no hay información disponible, el salario mínimo se estimó utilizando la econometría.

La masa neta de capital fijo no residencial se estimó por medio del método de inventario perpetuo. La fuente de información sobre la formación bruta de capital fijo (FBCF) desde 1947 hasta 1985 es IBGE (2003) y respecto de la etapa entre 1995 y 2008 es IBGE (2010). Para conectar ambas series, se utilizó un procedimiento similar al del cálculo del PIB para los años comprendidos entre 1986 y 1994. En cuanto a los años anteriores a 1947, la fuente de datos es Marquetti (2000). El método de inventario perpetuo empleado en este trabajo es similar al usado por la Oficina de Análisis Económicos. La tasa de depreciación se calcula como $R / T$, donde $R$ es la tasa de reducción del valor del activo y $\mathrm{T}$ es el tiempo de vida del activo. Hay dos diferencias principales en relación con la metodología de la Oficina de Análisis Económicos. En primer lugar, se considera que $R$ es igual a dos, de acuerdo con el método de depreciación decreciente doble. En segundo lugar, el activo se retira cuando alcanza su vida media. Debido a las enormes diferencias con respecto a la FBCF en máquinas y equipos y edificaciones no residenciales existentes entre IBGE (2003) e IBGE (2010), solo se considera un activo. La vida útil de ese activo es de 26 años. El consumo de capital fijo se mide como la suma de la masa neta de capital fijo y la FBCF al inicio del período, menos la masa neta de capital fijo al final del período.

\section{Bibliografia}

Cysne, R. (1998), "Aspectos macro e microeconômicos das reformas brasileiras", Ensaios Econômicos da EPGE, $\mathrm{N}^{\circ} 328$, Río de Janeiro, Fundación Getulio Vargas.

Duménil, G. y D. Lévy (2010), “The classical-Marxian evolutionary model of technical change: application to historical tendencies", Handbook of Alternative Theories of Economic Growth, M. Setterfield (ed.), Aldershot, Edward Elgar. (2004), Capital Resurgent. Roots of the Neoliberal Revolution, Cambridge, Harvard University Press.

(2003), "Technology and distribution: historical trajectories a la Marx", Journal of Economic Behavior \& Organization, vol. 52, $\mathrm{N}^{\circ} 2$, Amsterdam, Elsevier.

(1993), The Economics of the Profit Rate: Competition, Crises, and Historical Tendencies in Capitalism, Aldershot, Edward Elgar.

Felipe, J., E. Laviña y E. Fan (2008), "The diverging patterns of profitability, investment and growth of China and India during 1980-2003", World Development, vol. 36, N 5, Amsterdam, Elsevier.

Ferretti, F. (2008), "Patterns of technical change: a geometrical analysis using the wage-profit rate schedule", International Review of Applied Economics, vol. 22, N 5, Taylor \& Francis.

Foley, D. y A. Marquetti (1999), "Productivity, employment and growth in European integration", Metroeconomica, vol. 50, $\mathrm{N}^{\circ} 3$, Wiley.

(1997), "Economic growth from a classical perspective", Money, Growth, Distribution and Structural Change: Contemporaneous Analysis, J. Teixeira (ed.), Brasilia, Editora Universidade de Brasília.

Foley, D. y T. Michl (1999), Growth and Distribution, Cambridge, Harvard University Press.

Franco, G. (1998), "A inserção externa e o desenvolvimento", Revista de Economia Política, vol. 18, $\mathrm{N}^{\circ} 3$, julio-septiembre.
Furtado, C. (1983), Não à recessão e ao desemprego, Río de Janeiro, Paz e Terra.

Heston, A., R. Summers y B. Aten (2006), "Penn World Table Version 6.2", Center for International Comparisons of Production, Income and Prices [en línea] http://pwt.econ.upenn.edu8.

IBGE (Instituto Brasileño de Geografía y Estadística) (2010), Sistema de Contas Nacionais - Brasil 2004/2008, Río de Janeiro, CD-Rom.

(2003), Estatísticas do século XX, Río de Janeiro, CD-Rom. (1990), Estatísticas históricas do Brasil: séries econômicas, demográficas e sociais de 1550 a 1988, Río de Janeiro, Fundação Instituto Brasileiro de Geografia e Estatistica.

Loader, C. (1999), Local Regression and Likelihood, Nueva York, Springer-Verlag.

Marquetti, A. (2003), "Analyzing historical and regional patterns of technical change from a classical-Marxian perspective", Journal of Economic Behavior \& Organization, vol. 52, $\mathrm{N}^{\circ} 2$, Amsterdam, Elsevier.

(2002), "Progresso técnico, distribuição e crescimento na economia brasileira: 1955-1998", Estudos econômicos, vol. 32, $\mathrm{N}^{\circ}$ 1, São Paulo, Universidad de São Paulo. (2000), "Estimativa do estoque de riqueza tangível no Brasil, 1950-1998", Nova Economia, vol. 10, № 2, Belo Horizonte, Universidad Federal de Minas Gerais.

Okishio, N. (1961), "Technical change and the rate of profit", Kobe University Economic Review, vol. 7, Hyogo, Universidad de Kobe.

Sraffa, P. (1960), Production of Commodities by Means of Commodities, Cambridge, Cambridge University Press.

Williamson, J. (1992), "Reformas políticas na América Latina na década de 80", Revista de Economia Política, vol. 12, $\mathrm{N}^{\circ} 45$, São Paulo. 